\title{
Aberrant expression of histone deacetylase 6 in oral squamous cell carcinoma
}

\author{
TAKUMI SAKUMA ${ }^{1}$, KATSUHIRO UZAWA $^{2,4}$, TAKESHI ONDA ${ }^{1}$, MASASHI SHIIBA $^{4}$, \\ HIDETAKA YOKOE $^{4}$, TAKAHIKO SHIBAHARA ${ }^{1}$ and HIDEKI TANZAWA ${ }^{2-4}$ \\ ${ }^{1}$ Department of Oral and Maxillo-Facial Surgery, Tokyo Dental College, 1-2-2 Masago, Mihama-ku, Chiba 261-8502; \\ ${ }^{2}$ Department of Clinical Molecular Biology, ${ }^{3}$ Center of Excellence (COE) Program in the 21 st Century, \\ Graduate School of Medicine, Chiba University; ${ }^{4}$ Division of Dentistry and Oral-Maxillofacial Surgery, \\ Chiba University Hospital, 1-8-1 Inohana, Chuo-ku, Chiba 260-8670, Japan
}

Received February 2, 2006; Accepted March 31, 2006

\begin{abstract}
The structure and function of chromatin can be altered by modifications to histone. Histone acetylation is a reversible process governed by histone acetyltransferases and histone deacetylases (HDACs). HDAC6 is a subtype of the HDAC family that deacetylates $\alpha$-tubulin and increases cell motility. We investigated the expression levels of HDAC6 mRNA and protein expression in oral squamous cell carcinoma (OSCC)-derived cell lines and human primary OSCCs to elucidate the potential involvement of HDAC6 in OSCC. Using quantitative real-time reverse transcription polymerase chain reaction and Western blots on nine OSCC-derived cell lines and normal oral keratinocytes (NOKs), HDAC6 mRNA and protein expression were commonly up-regulated in all cell lines compared with the NOKs. Immunofluorescence analysis detected HDAC6 protein in the cytoplasm of OSCC cell lines. Similar to OSCC cell lines, high frequencies of HDAC6 up-regulation were evident in both mRNA (74\%) and protein $(51 \%)$ levels of primary tumors. Among the clinical variables analyzed, the clinical tumor stage was found to be associated with the HDAC6 expression states. The analysis indicated a significant difference in the HDAC6 expression level between the early stage (stage I and II) and advancedstage (stage III and IV) tumors $(\mathrm{P}=0.014)$. These results suggest that HDAC6 expression may be correlated with tumor aggressiveness and offer clues to the planning of new treatments.
\end{abstract}

Correspondence to: Dr Katsuhiro Uzawa, Department of Clinical Molecular Biology, Graduate School of Medicine, Chiba University, 1-8-1 Inohana, Chuo-ku, Chiba 260-8670, Japan

E-mail: uzawak@faculty.chiba-u.jp

Key words: HDAC6, oral squamous cell carcinoma, quantitative real-time RT-PCR, Western blotting, immunofluorescence, immunohistochemistry

\section{Introduction}

Oral cancer accounts for $3 \%$ of all cancers worldwide (1). In addition, oral squamous cell carcinoma (OSCC) is the most frequently occurring malignancy in the oral cavity. A number of etiologic factors have been implicated in the development of OSCCs, such as the use of tobacco, alcohol, or the presence of incompatible prosthetic materials $(2,3)$. However, some patients develop OSCC without risk factors, which suggests that host susceptibility may play a role. Molecular alterations in a number of oncogenes and tumor suppressor genes associated with the development of OSCC could be important clues for addressing these problems $(4,5)$.

In eukaryotes, the DNA in the cell nucleus is bound by histones and other chromosomal proteins to form a highly organized and compact structure called chromatin (6). The structure and function of chromatin can be modified by many factors, of which the most extensively studied are histone acetylation and deacetylation. This dynamic reversible process is governed by histone acetyltransferases (HATs) and histone deacetylases (HDACs) $(7,8)$. The correlation between acetylation and increased transcription has been known for many years. Highly acetylated histones are associated with transcriptionally active chromatin, whereas hypoacetylated histones are associated with inactive chromatin and transcriptional silencing $(9,10)$. There is increasing evidence that alternations in HAT and HDAC activity occur in human cancers $(11,12)$. HDACs mediate the function of oncogenic translocation products in specific forms of leukemia (12) and lymphoma (13). Based on structural and functional sequence considerations, HDACs are grouped into three classes: I, II (A and B), and III $(14,15)$. HDAC6, predominantly a cytoplasmic, microtubule-associated member of the class IIB family of HDACs (16), is a unique isoform among the HDACs, because it contains two catalytic domains, compared with one catalytic domain found in other HDACs $(17,18)$. Furthermore, HDAC6 is located exclusively in the cytoplasm and deacetylates $\alpha$-tubulin in polymerized microtubules (19-21). HDAC6 enhances chemotactic cellular motility through the deacetylation of $\alpha$-tubulin, indicating that HDAC6 is related to cell migration rather than to transcriptional regulation 
Table I. Primer pairs for qRT-PCR.

\begin{tabular}{llll}
\hline Gene name & Forward primer & Reverse primer & Size (bp) \\
\hline HDAC6 & 5'-CAGAACTGGTGCTGGTCTCAG-3' & 5'-TATCTGCGATGGACTTGGATG-3' & 295 \\
GAPDH & 5'-CATCTCTGCCCCCTCTGCTGA-3' & 5'-GGATGACCTTGCCCACAGCCT-3' & 305 \\
\hline
\end{tabular}

bp, base pair.

$(19,20)$. HDAC6 expression has been reported in benign and malignant breast epithelium (22). These findings led us to hypothesize that altered HDAC6 expression or biologic activity might be associated with malignant transformation. Regarding OSCC, it is unknown whether HDAC6 is associated with oral carcinogenesis. Thus, we selected HDAC6 for investigation.

In the present study, the HDAC6 expression states of the mRNA and protein in OSCCs were evaluated by quantitative real-time reverse transcription polymerase chain reaction (qRT-PCR), Western blotting, and immunofluorescence on nine OSCC-derived cell lines. In addition, we analyzed the mRNA and protein in primary OSCCs by qRT-PCR and immunohistochemistry.

\section{Materials and methods}

Cells. The nine human OSCC-derived cell lines used in this study were Ca9-22, Ho-1-N-1, HSC-2, HSC-3, HSC-4, SAS (Human Science Research Resources Bank, Osaka, Japan), OK92 (established from carcinoma of the tongue in our department), Sa3, and H1 (provided by Dr Shigeyuki Fujita, Wakayama Medical University, Wakayama, Japan). All cell lines were maintained at $37^{\circ} \mathrm{C}$ (humidified atmosphere $5 \%$ $\mathrm{CO}_{2} / 95 \%$ air) and cultured in Dulbecco's modified Eagle's medium F-12 HAM (Sigma Chemical Co., St. Louis, MO) with $10 \%$ fetal bovine serum (Sigma) and 50 units $/ \mathrm{ml}$ of penicillin and streptomycin (Sigma). Healthy oral gingival specimens were collected from patients, aged 22 to 35 years, at Chiba University Hospital. The institutional review board of Chiba University approved all relevant protocols. Two independent human normal oral keratinocytes (HNOKs) were primary cultured and maintained in defined keratinocyte-SFM (Gibco BRL, Gaithersburg, Germany) (23).

Tissue samples. Tumors with patient-matched normal oral tissues, where available, were obtained at the time of surgical resection at Chiba University Hospital after informed consent was obtained from the patients, according to a protocol that was approved by the institutional review board of Chiba University. The respected tissues were divided into two parts: one was frozen immediately and stored at $-80^{\circ} \mathrm{C}$ until use, and the other was fixed in $10 \%$ buffered formaldehyde solution for pathologic diagnosis. Histopathologic diagnosis of each cancer tissue was performed according to the International Histological Classification of Tumours by the Department of Pathology, Chiba University Hospital. Clinicopathologic staging was determined by the tumor node metastasis (TNM) classification of the International Union against Cancer. All patients had OSCC that was histologically confirmed, and tumor samples were checked to ensure the presence of tumor tissue in more than $80 \%$ of the specimen.

$m R N A$ expression analysis. Total RNA was isolated from cells using TRIzol reagent (Invitrogen, Carlsbad, CA), and reverse transcribed using Ready-to-Go You-Prime first-strand beads (Amersham Biosciences, Little Chalfont, Buckinghamshire, UK) and oligo (dT) primer (Sigma Genosys, Ishikari, Japan) (24). qRT-PCR was performed to evaluate the expression level of HDAC6 mRNA in the nine OSCC-derived cell lines, NOKs, tumors, and paired normal oral tissues from 50 patients with OSCC using a LightCycler FastStart DNA Master SYBR Green I kit (Roche Diagnostics GmbH, Mannheim, Germany), according to the procedure described by the manufacturer. The PCR reactions using LightCycler (Roche) apparatus were carried out in a final volume of a $20-\mu 1$ reaction mixture consisting of $2 \mu \mathrm{l}$ FastStart DNA Master SYBR Green I mix, $3 \mathrm{mM} \mathrm{MgCl}_{2}$, and $0.2 \mu 1$ of each primer, according to the manufacturer's instructions. The reaction mixture was loaded into glass capillary tubes and submitted to an initial denaturation at $95^{\circ} \mathrm{C}$ for $10 \mathrm{~min}$, followed by 45 rounds of amplification at $95^{\circ} \mathrm{C}$ for $10 \mathrm{sec}$ for denaturation, $62^{\circ} \mathrm{C}$ for $10 \mathrm{sec}$ for annealing, and $72^{\circ} \mathrm{C}$ for extension, with a temperature slope of $20^{\circ} \mathrm{C} / \mathrm{sec}$, performed in the LightCycler. The transcript amount for the HDAC6 gene was estimated from the respective standard curves and normalized to the glyceraldehyde-3phosphate dehydrogenase (GAPDH) transcript amount determined in corresponding samples. Table I shows the gene-specific nucleotide sequences for qRT-PCR. The statistical significance of the gene expression levels between tumors and oral normal tissues was calculated with the MannWhitney's U test. $\mathrm{P}<0.05$ was considered significant.

Western blot analysis. We also evaluated the protein expression status by Western blot analysis. Briefly, the OSCC cell lines and the NOKs were lysed in buffer [10 mM Tris-base ( $\mathrm{pH} 8.0$ ), $400 \mathrm{mM} \mathrm{NaCl}, 3 \mathrm{mM} \mathrm{MgCl}{ }_{2}, 0.5 \%$ NP-40 (Sigma), $100 \mathrm{mM}$ phenylmethylsulfonyl fluoride, and $0.01 \%$ protease inhibitor cocktail (Sigma)] at $4^{\circ} \mathrm{C}$ for $10 \mathrm{~min}$. Cell extracts were centrifuged at $15,000 \mathrm{rpm}$ for $15 \mathrm{~min}$ at $4^{\circ} \mathrm{C}$. The supernatant containing the cell protein then was recovered and the protein concentration was measured with a Protein Assay Kit (Bio-Rad Laboratories, Hercules, CA) and adjusted to $1 \mathrm{mg} / \mathrm{ml}$. Protein extracts were electrophoresed on $11 \%$ sodium dodecyl sulfatepolyacrylamide gel electrophoresis gels, transferred to PVDF membranes (Bio-Rad), and blocked for $1 \mathrm{~h}$ at room temperature in 5\% skimmed milk. Immunoblot PVDF membranes were washed with $0.1 \%$ Tween-20 in TBS (TBS-T) five times and 
incubated with a 1:100 dilution of affinity-purified goat antiHDAC6 polyclonal antibody (Santa Cruz Biotechnology, Santa Cruz, CA) for $2 \mathrm{~h}$ at room temperature. PVDF membranes were washed again and incubated with a 1:1000 of horseradish peroxidase-conjugated anti-goat IgG Ab (Santa Cruz Biotechnology) as a secondary antibody for $30 \mathrm{~min}$ at room temperature. Finally, the membranes were incubated with enhanced chemiluminescence (ECL)+ horseradish peroxidase substrate solution included in the $\mathrm{ECL}^{+}$kit (Amersham Biosciences), and immunoblotting was visualized by exposing the membrane to X-ray film $(25,26)$. HeLa cells served as positive controls.

Immunofluorescence. Cells were grown on glass coverslips, washed with phosphate-buffered saline (PBS) and fixed in $4 \%$ paraformaldehyde for $10 \mathrm{~min}$ at $37^{\circ} \mathrm{C}$ followed by absolute methanol for $10 \mathrm{~min}$ at $4^{\circ} \mathrm{C}$, and permeabilized in $0.01 \%$ Triton X-100 in PBS for $10 \mathrm{~min}$. Non-specific binding was blocked with $5 \%$ skim milk in PBS for $1 \mathrm{~h}$. Cells were incubated for $2 \mathrm{~h}$ with goat anti-HDAC6 polyclonal antibody (Santa Cruz Biotechnology) at a dilution of 1:100, washed with PBS, and incubated with rabbit anti-goat secondary antibody labeled with Alexa Fluor 488 (Molecular Probes, Leiden, the Netherlands) for $1 \mathrm{~h}$. Coverslips were examined by fluorescence microscopy. The microscope used was a Leica DMIRBE inverted stand equipped with a Leica TCS2MP confocal system (Leica Laserteknik, Mannheim, Germany) and Coherent Mira tunable pulsed titanium sapphire laser (Coherent Laser Group, Santa Clara, CA) (26).

Immunohistochemistry. Immunohistochemistry staining was performed on $4-\mu \mathrm{m}$ paraffin-embedded specimens. Briefly, after deparaffinization and hydration, unmasked HDAC6 antigen was microwaved in $10 \mathrm{mM}$ sodium citrate buffer ( $\mathrm{pH}$ 6.0) and rinsed three times in PBS solution. After quenching the endogenous peroxidase in $0.3 \% \mathrm{H}_{2} \mathrm{O}_{2}$ for $30 \mathrm{~min}$ and blocking the sections for $2 \mathrm{~h}$ at room temperature with $1.5 \%$ blocking serum (Santa Cruz Biotechnology) in PBS, the sections were reacted with goat anti-HDAC6 polyclonal antibody (Santa Cruz Biotechnology) at a dilution of 1:300 overnight at $4^{\circ} \mathrm{C}$ in a moist chamber. The sections were washed three times with PBS and incubated for 30 min with biotinylated secondary antibody at 1:200 in PBS containing 1.5\% normal donkey serum. After rinsing with PBS, the sections were incubated with avidin coupled to biotinylated horseradish peroxidase for $30 \mathrm{~min}$, rinsed, and reacted with the chromogenic substrate DAB for $1 \mathrm{~min}$. Finally, the slides were lightly counterstained with hematoxylin, dehydrated with ethanol, cleaned with xylene, and mounted. The ABC Staining System (Santa Cruz Biotechnology) was used. As a negative control, duplicate sections were immunostained without exposure to primary antibodies. To quantitate the state of HDAC6 protein expression, a scoring method was used in which the mean percentage of positive tumor cells was determined in at least five random fields at magnification $\mathrm{x} 400$ in each section. The intensity of the HDAC6 immunoreaction was scored as follows: $1+$, weak; $2+$, moderate; and $3+$, intense. The percentage of positive tumor cells and the staining intensity were multiplied to produce an HDAC6-immunohistochemistry staining score $(27,28)$. Cases with an HDAC6 score $<80.2$
A

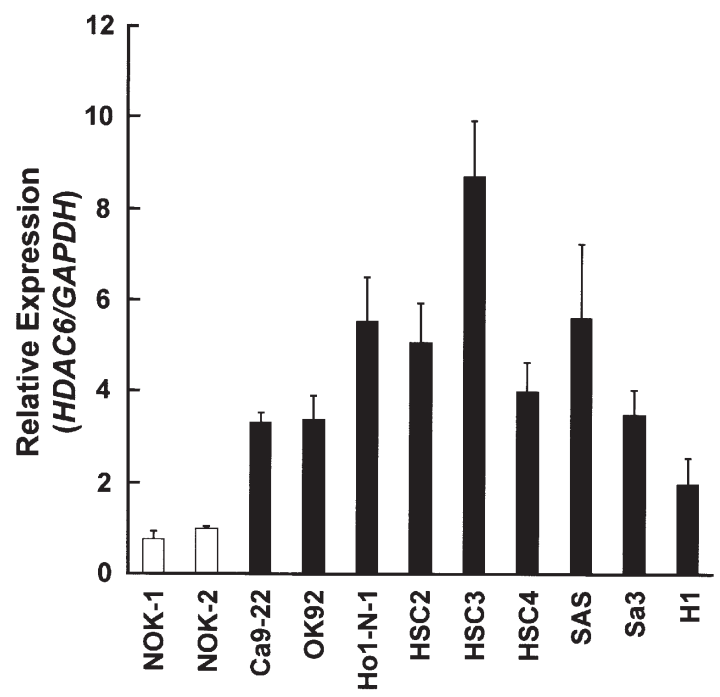

B

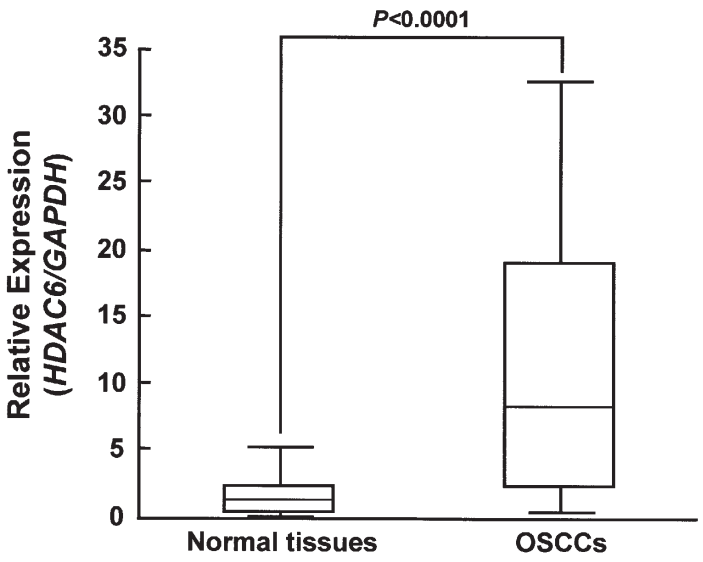

Figure 1. HDAC6 mRNA expression status in OSCC-derived cell lines and primary OSCCs. (A) Quantification of mRNA levels in OSCC-derived cell lines by qRT-PCR analysis. Significant up-regulation of the HDAC6 mRNA expression is seen in all cell lines examined compared to HDAC6 mRNA expression in the NOKs. Data are expressed as the means \pm SD. (B) Comparison of HDAC6 mRNA expression levels between primary OSCCs and matched normal tissues. The relative mRNA expression levels in the normal tissues $(\mathrm{n}=50)$ and primary OSCCs $(\mathrm{n}=50)$ range from 0.002 to 5.20 (median 1.25) and 0.50 to 32.47 (median 8.18), respectively. A significantly higher HDAC6 expression is detected in primary OSCCs than matched normal tissues ( $\mathrm{P}<0.0001$; Mann-Whitney's U test).

(the highest score of normal tissues) were considered negative. These judgments were made by two independent pathologists, neither of whom had any information pertaining to the patients' clinical status. Statistical significance was evaluated by the Fisher's exact test or Mann-Whitney's U test. $\mathrm{P}<0.05$ was considered significant.

\section{Results}

$m R N A$ expression analysis. We examined the expression levels of HDAC6 mRNA in nine OSCC-derived cell lines, NOKs, primary tumors and paired normal oral tissues from 50 patients with OSCC using qRT-PCR analysis. Significant up-regulation of HDAC6 expression was observed in all OSCC cell lines examined compared with the NOKs used as a control (Fig. 1A). Data are expressed as the means \pm SD of 
A

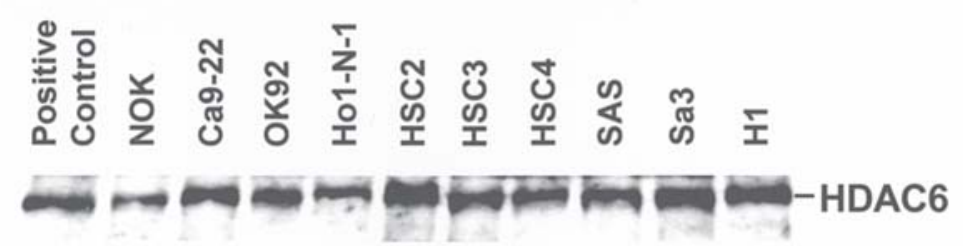

B


C
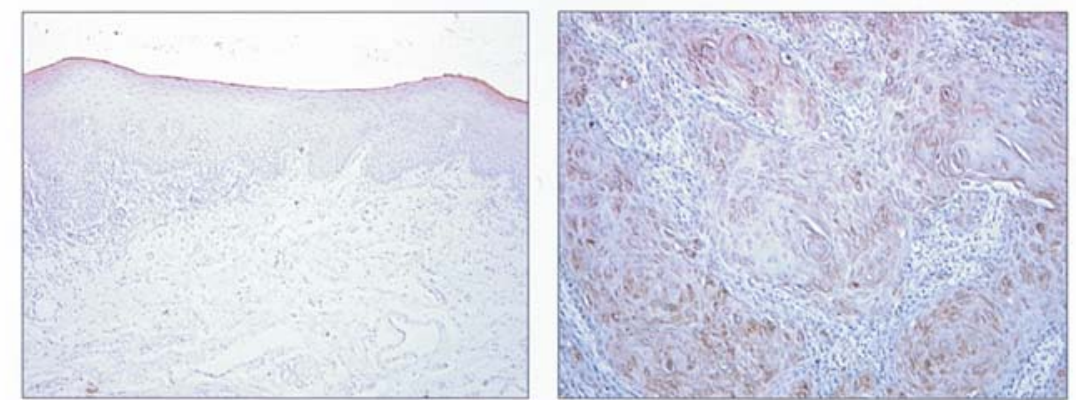

Figure 2. Representative results of expression and localization of HDAC6 protein in OSCC-derived cell lines, normal tissues and primary OSCCs. (A) Western blot analysis of HDAC6 protein in the OSCC-derived cell lines and the NOKs. HDAC6 protein expression is up-regulated in OSCC cell lines compared with NOKs. (B) Immunocytochemical analysis shows HDAC6 protein localization in the HSC2 cell line and the NOKs. Strong immunoreactivity of HDAC6 protein is detected in the cytoplasm of HSC2 cell line compared with the NOKs. (C) Immunohistochemical staining of HDAC6 in normal oral tissue. Normal oral tissue shows weak expression of HDAC6 protein. (D) Immunohistochemical staining of HDAC6 in primary OSCC. Primary OSCC tissue shows strong cytoplasmic staining of the tumor cells. Original magnification, x100.

two independent experiments with samples in triplicate. In addition, similar to the OSCC cells, the HDAC6 expression levels were up-regulated in primary tumors compared with matched normal tissues $(\mathrm{P}<0.0001$; Mann-Whitney's U test) (Fig. 1B). qRT-PCR analysis revealed up-regulation of HDAC6 expression in $37(74 \%)$ of 50 primary OSCCs compared with matched normal tissue. The relative mRNA expression levels in the normal tissues and primary OSCCs ranged from 0.002 to 5.20 (median, 1.25) and 0.50 to 32.47 (median, 8.18), respectively.

Western blot analysis. To investigate HDAC6 protein expression status in the nine OSCC-derived cell lines and the NOKs, we performed Western blot analysis. Fig. 2A shows representative results of the analysis. The size of the band was detected as $131 \mathrm{kDa}$, as reported by Grozinger et al (18).
A significant increase in HDAC6 expression was observed in all OSCC cell lines compared with the NOKs used as a control.

Immunofluorescence. To assess HDAC6 protein localization, we performed immunofluorescence analysis. The results of Western blot analysis showed that the HSC2 cell line was upregulated more than three-fold compared with the NOKs and had the highest expression of HDAC6 of the nine OSCCsderived cell lines. For this reason, we selected the HSC2 cell line for immunofluorescence analysis. Strong immunoreactivity of HDAC6 protein was detected in the cytoplasm of the HSC2 cell line compared with the NOKs (Fig. 2B).

Immunohistochemistry. Ninety patients with OSCC were identified for whom there was adequate histologic material 
Table II. Correlation between the expression of HDAC6 and clinical classification in OSCCs.

\begin{tabular}{|c|c|c|c|c|}
\hline \multirow[b]{2}{*}{ Clinical classification } & \multicolumn{4}{|c|}{ Results of immunostaining: no. of patients (\%) } \\
\hline & Total & HDAC6 (-) & HDAC6 (+) & P-value \\
\hline \multicolumn{5}{|l|}{ Age at surgery (year) } \\
\hline$<60$ & 30 & $10(33)$ & $20(67)$ & \multirow[t]{3}{*}{0.097349} \\
\hline $60-70$ & 28 & $15(54)$ & $13(46)$ & \\
\hline$>70$ & 32 & $19(59)$ & $13(41)$ & \\
\hline \multicolumn{5}{|l|}{ Gender } \\
\hline Male & 52 & $24(46)$ & $28(54)$ & \multirow[t]{2}{*}{0.669873} \\
\hline Female & 38 & $20(53)$ & $18(47)$ & \\
\hline \multicolumn{5}{|l|}{ T-primary tumor } \\
\hline $\mathrm{T} 1$ & 6 & $4(67)$ & $2(33)$ & \multirow[t]{4}{*}{0.421286} \\
\hline $\mathrm{T} 2$ & 46 & $24(52)$ & $22(48)$ & \\
\hline $\mathrm{T} 3$ & 15 & $8(53)$ & $7(47)$ & \\
\hline $\mathrm{T} 4$ & 23 & $8(35)$ & $15(65)$ & \\
\hline $\mathrm{T} 1+\mathrm{T} 2$ & 52 & $28(54)$ & $24(46)$ & 0.293605 \\
\hline $\mathrm{T} 3+\mathrm{T} 4$ & 38 & $16(42)$ & $22(58)$ & \\
\hline \multicolumn{5}{|l|}{ N-regional lymph node } \\
\hline N (-) & 55 & $30(55)$ & $25(45)$ & \multirow[t]{2}{*}{0.200436} \\
\hline $\mathrm{N}(+)$ & 35 & $14(40)$ & $21(60)$ & \\
\hline \multicolumn{5}{|l|}{ Stage } \\
\hline I & 5 & $3(60)$ & $2(40)$ & \multirow[t]{4}{*}{0.075183} \\
\hline II & 26 & $18(69)$ & $8(31)$ & \\
\hline III & 17 & $7(41)$ & $10(59)$ & \\
\hline IV & 42 & $16(38)$ & $26(62)$ & \\
\hline $\mathrm{I}+\mathrm{II}$ & 31 & $21(68)$ & $10(32)$ & 0.014252 \\
\hline III + IV & 59 & $23(39)$ & $36(61)$ & \\
\hline \multicolumn{5}{|l|}{ Histopathologic type } \\
\hline Well differentiated & 59 & $30(51)$ & $29(49)$ & \multirow[t]{3}{*}{0.830906} \\
\hline Moderately differentiated & 25 & $12(48)$ & $13(52)$ & \\
\hline Poorly differentiated & 6 & $2(33)$ & $4(67)$ & \\
\hline \multicolumn{5}{|l|}{ Tumor site } \\
\hline Gingiva & 27 & $13(48)$ & $14(52)$ & \multirow[t]{7}{*}{1.000000} \\
\hline Tongue & 39 & $20(51)$ & $19(49)$ & \\
\hline Buccal mucosa & 9 & $4(44)$ & $5(56)$ & \\
\hline Oral floor & 7 & $4(57)$ & $3(43)$ & \\
\hline Oropharyngeal isthmus & 7 & $3(43)$ & $4(57)$ & \\
\hline Lower lip & 1 & $0 \quad(0)$ & $1(100)$ & \\
\hline Soft palate & 0 & $0 \quad(0)$ & $0 \quad(0)$ & \\
\hline
\end{tabular}

available for immunohistochemical analysis. The correlation between the clinicopathologic characteristics of patients with OSCC and HDAC6 expression status is summarized in Table II.
Among the tumors examined, 46 of 90 cases $(51 \%)$ had a strong HDAC6 immunoreaction in the cytoplasm of the tumor cells (Table II). Representative results for HDAC6 
A

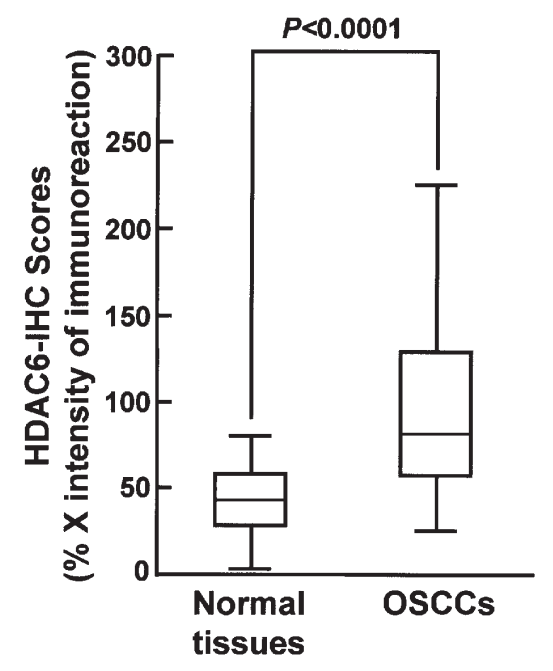

B

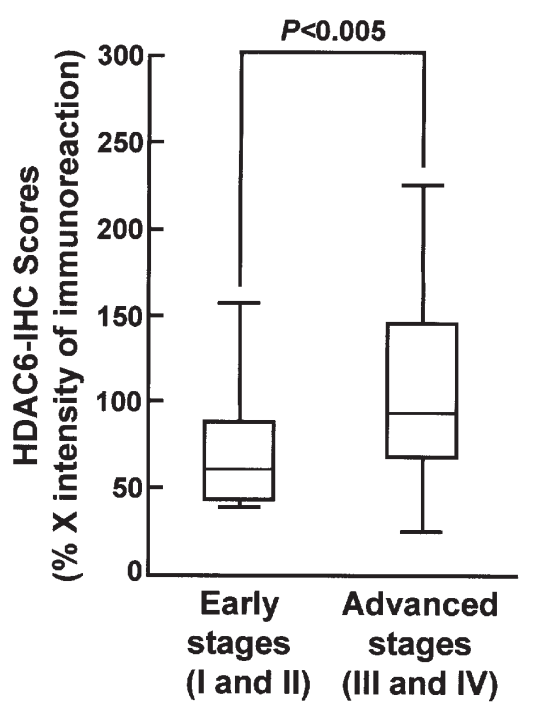

C

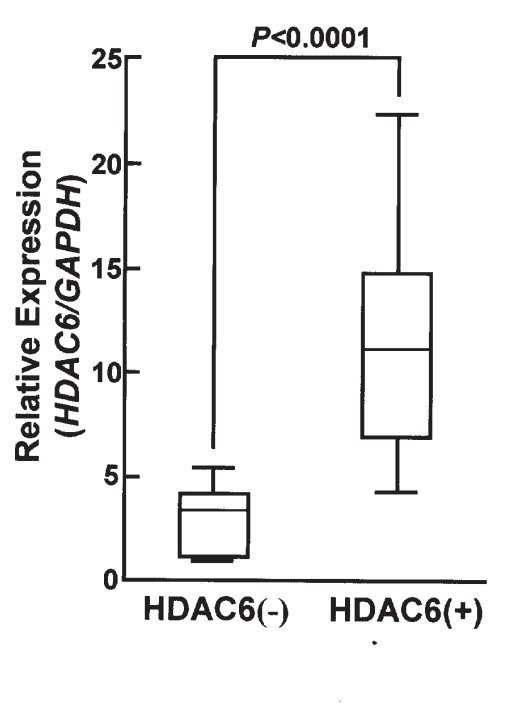

Figure 3. (A) State of HDAC6 protein expression in normal oral tissues ( $\mathrm{n}=90$ ), and primary OSCCs (n=90). The HDAC6-immunohistochemistry scores are calculated as follows: HDAC6-immunohistochemistry score $=$ the mean percentage of positive tumor cells $\mathrm{x}$ staining intensity. The HDAC6 immunohistochemistry scores for normal tissues and OSCCs range from 2.2 to 80.2 (median 42.2) and 24.7 to 225.4 (median 81.1 ), respectively (P<0.0001; Mann-Whitney's U test). (B) Association between HDAC6 protein expression and TNM classification. The HDAC6 immunohistochemistry scores for early stages (I and II) OSCC ( $\mathrm{n}=31$ ) and advanced stages (III and IV) OSCC ( $=59$ ) range from 38.1 to 156.9 (median 60.6) and 24.7 to 225.4 (median 92.5), respectively ( $\mathrm{P}<0.005$; Mann-Whitney's U test). (C) Comparison of HDAC6 mRNA expression levels between HDAC6-positive (n=15) and HDAC6-negative $(\mathrm{n}=14)$ cases classified by immunohistochemistry analysis. Relative mRNA expression levels in negative and positive cases range from 1.1 to 5.5 (median 3.3$)$ and 4.3 to 22.2 (median 11.1), respectively ( $\mathrm{P}<0.0001$; Mann-Whitney's U test). IHC, immunohistochemistry.

protein expression in normal oral tissue and primary OSCC are shown in Fig. 2C and D. The HDAC6 immunohistochemistry scores for normal tissues and OSCCs ranged from 2.2 to 80.2 (median, 42.2) and 24.7 to 225.4 (median, 81.1), respectively. The HDAC6 expression levels in primary OSCCs were markedly higher than those in normal oral tissues $(\mathrm{P}<0.0001$; Mann-Whitney's U-test) (Fig. 3A). Moreover, HDAC6 immunoreactivity was correlated with TNM stages $(\mathrm{P}=0.014)$ (Table II). The analysis indicated a difference in HDAC6 expression levels between early stages (stages I and II) and advanced-stages (stages III and IV) tumors. The HDAC6 immunohistochemistry scores for the early stage and advanced-stage tumors ranged from 38.1 to 156.9 (median, 60.6) and 24.7 to 225.4 (median, 92.5), respectively. The HDAC6 expression levels were higher in the OSCC group with advanced stage disease than the group with early stage disease ( $\mathrm{P}<0.005$; Mann-Whitney's U test) (Fig. 3B). qRT-PCR data showed a significant relationship with protein expression levels by immunohistochemistry. HDAC6 mRNA expression levels increased in primary tumors of HDAC6positive cases $(\mathrm{n}=15)$ compared with HDAC6-negative cases $(\mathrm{n}=14)(\mathrm{P}<0.0001$; Mann-Whitney's U test) (Fig. 3C). Relative mRNA expression levels in negative and positive cases ranged from 1.1 to 5.5 (median, 3.3) and from 4.3 to 22.2 (median, $11.1)$, respectively.

\section{Discussion}

HDACs are a family of enzymes whose functions have been associated with gene expression and chromatin dynamics by catalyzing the removal of the acetyl modification from lysine residues of histone $(29,30)$. However, HDACs might also deacetylate nonhistone proteins, such as p53, tubulin, various transcription factors, and others (31-33). Recent evidence indicates that not all functions of HDACs are dedicated to regulating gene transcription and chromatin remodeling (16). Furthermore, HDACs have attracted attention not only for their role in transcriptional control but also because their pharmacologic inhibition was found to have pleiotropic effects, such as induction of cell differentiation and arrest of cellular growth (34). In addition, HDAC activity was elevated in a number of tumors, potentially leading to deregulation of tumor suppressor genes (35). Thus, HDACs are considered to be valuable targets for cancer treatment $(35,36)$. Thus far, more than 10 proteins with HDAC activity have been identified in mammalian cells. They are divided into three classes, based on sequence homology, intracellular localization, and association with the protein that forms the DNA-binding complex $(37,38)$. On the basis of its similarity to the yeast gene Hda1, HDAC6 is designated class IIB $(17,18)$. HDAC6 is a unique deacetylase because it contains two functional catalytic domains, and the C-terminal catalytic domain possesses $\alpha$-tubulin deacetylase activity (39).

Recent studies have reported that fluorescence in situ hybridization analysis localized the human HDAC6 gene to the sub-band border of chromosome Xp11.22-23, a region characterized by frequent gains and losses of chromosomal material in several types of cancer (40). In addition, HDAC6 deacetylates $\alpha$-tubulin in polymerized microtubules, thus potentially enhancing chemotactic cell motility $(19,20)$. Yoshida et al reported that HDAC6 was expressed in benign and malignant breast epithelium, and higher levels of HDAC6 
expression correlated with a poor prognosis in patients who are estrogen receptor-positive by means of immunohistochemistry (22).

In the present study, to clarify its relative contribution to OSCC, we investigated the HDAC6 mRNA and protein expression status in OSCC-derived cell lines, NOKs, human primary OSCCs, and corresponding normal oral tissues using qRT-PCR, Western blot analysis, immunofluorescence, and immunohistochemistry. Up-regulation of HDAC6 mRNA and protein expression status was found in OSCC-derived cell lines compared with the NOKs. We also detected a comparatively strong tumor cell-localized cytoplasmic HDAC6 immunoreaction in OSCC cell lines and primary OSCCs. Similar to OSCC cell lines, by evaluating the HDAC6 immunohistochemistry scores and relative mRNA expression, HDAC6 was significantly enhanced in the primary OSCCs compared with normal tissues. Furthermore, qRT-PCR analysis data showed strongly linked corresponding protein expression levels by immunohistochemical analysis (Fig. 3C). We also found a correlation between HDAC6 protein expression status and the clinicopathologic features. The HDAC6 protein expression levels in primary OSCCs were significantly associated with TNM stages $(\mathrm{P}=0.014)$. The HDAC6 expression levels differed between the early stages (stage I and II) and advanced stages (stage III and IV) tumors $(\mathrm{P}<0.005$; Mann-Whitney's U test) (Fig. 3B). Our results suggest an association between HDAC6 expression levels and the clinical tumor stage, with up-regulation of HDAC6 expression in the advanced stages of OSCC. Based on these findings, HDAC6 overexpression may play a role in tumor aggressiveness and progression of OSCC.

In conclusion, the expression of HDAC6 was frequently up-regulated in OSCC. The differential expression of HDAC6 between the early and advanced stage of OSCC may provide insight into the process of carcinogenesis and for planning new treatment strategies.

\section{Acknowledgments}

This study was partly supported by the 21 st Century COE Programs Grant from the Ministry of Education, Culture, Sports, Science and Technology of Japan. We thank Lynda C. Charters for editing this manuscript.

\section{References}

1. Parkin DM, Bray F, Ferlay $\mathrm{J}$ and Pisani P: Global cancer statistics, 2002. CA Cancer J Clin 55: 74-108, 2005.

2. Macfarlane GJ, Zheng T, Marshall JR, et al: Boyle P. Alcohol, tobacco, diet and the risk of oral cancer: a pooled analysis of three case-control studies. Eur J Cancer B Oral Oncol 31: 181-187, 1995.

3. Mashberg A, Boffetta P, Winkelman R and Garfinkel L: Tobacco smoking, alcohol drinking, and cancer of the oral cavity and oropharynx among U.S. veterans. Cancer 72: 1369-1375, 1993.

4. Fearon ER and Vogelstein B: A genetic model for colorectal tumorigenesis. Cell 61: 759-767, 1990.

5. Marshall CJ: Tumor suppressor genes. Cell 64: 313-326, 1991.

6. Jenuwein T and Allis CD: Translating the histone code. Science 293: 1074-1080, 2001.

7. Thiagalingam S, Cheng KH, Lee HJ, Mineva N, Thiagalingam A and Ponte JF: Histone deacetylases: unique players in shaping the epigenetic histone code. Ann NY Acad Sci 983: 84-100, 2003.
8. Wolffe AP: Chromatin remodeling: why it is important in cancer. Oncogene 20: 2988-2990, 2001.

9. Loidl P: Towards an understanding of the biological function of histone acetylation. FEBS Lett 227: 91-95, 1988.

10. Roth SY, Denu JM and Allis CD: Histone acetyltransferases. Annu Rev Biochem 70: 81-120, 2001.

11. Timmermann S, Lehrmann H, Polesskaya A and Harel-Bellan A: Histone acetylation and disease. Cell Mol Life Sci 58: 728-736, 2001.

12. Pandolfi PP: Transcription therapy for cancer. Oncogene 20: 3116-3127, 2001

13. Dhordain P, Lin RJ, Quief S, Lantoine D, Kerckaert JP, Evans RM and Albagli O: The LAZ3(BCL-6) oncoprotein recruits a SMRT/ mSIN3A/histone deacetylase containing complex to mediate transcriptional repression. Nucleic Acids Res 26: 4645-4651, 1998.

14. Gray SG and Ekstrom TJ: The human histone deacetylase family. Exp Cell Res 262: 75-83, 2001.

15. Zhou X, Marks PA, Rifkind RA and Richon VM: Cloning and characterization of a histone deacetylase, HDAC9. Proc Natl Acad Sci USA 98: 10572-10577, 2001.

16. Verdin E, Dequiedt F and Kasler HG: Class II histone deacetylases: versatile regulators. Trends Genet 19: 286-293, 2003.

17. Verdel A and Khochbin S: Identification of a new family of higher eukaryotic histone deacetylases. Coordinate expression of differentiation-dependent chromatin modifiers. J Biol Chem 274: 2440-2445, 1999.

18. Grozinger CM, Hassig CA and Schreiber SL: Three proteins define a class of human histone deacetylases related to yeast Hda1p. Proc Natl Acad Sci USA 96: 4868-4873, 1999.

19. Hubbert C, Guardiola A, Shao R, et al: HDAC6 is a microtubuleassociated deacetylase. Nature 417: 455-458, 2002.

20. Haggarty SJ, Koeller KM, Wong JC, Grozinger CM and Schreiber SL: Domain-selective small-molecule inhibitor of histone deacetylase 6 (HDAC6)-mediated tubulin deacetylation. Proc Natl Acad Sci USA 100: 4389-4394, 2003.

21. Matsuyama A, Shimazu T, Sumida Y, et al: In vivo destabilization of dynamic microtubules by HDAC6-mediated deacetylation. EMBO J 21: 6820-6831, 2002.

22. Yoshida N, Omoto Y, Inoue A, et al: Prediction of prognosis of estrogen receptor-positive breast cancer with combination of selected estrogen-regulated gene. Cancer Sci 95: 496-502, 2004.

23. Koike H, Uzawa K, Nakashima D, et al: Identification of differentially expressed proteins in oral squamous cell carcinoma using a global proteomic approach. Int J Oncol 27: 59-67, 2005.

24. Kasamatsu A, Uzawa K, Shimada K, et al: Elevation of galectin-9 as an inflammatory response in the periodontal ligament cells exposed to Porphylomonas gingivalis lipopolysaccharide in vitro and in vivo. Int J Biochem Cell Biol 37: 397-408, 2005.

25. Endo Y, Uzawa K, Mochida Y, Shiiba M, Bukawa H, Yokoe H and Tanzawa H: Sarcoendoplasmic reticulum Ca (2+) ATPase type 2 downregulated in human oral squamous cell carcinoma. Int J Cancer 110: 225-231, 2004.

26. Kasamatsu A, Uzawa K, Nakashima D, et al: Galectin-9 as a regulator of cellular adhesion in human oral squamous cell carcinoma cell lines. Int J Mol Med 16: 269-273, 2005.

27. Shimada K, Uzawa K, Kato M, et al: Aberrant expression of RAB1A in human tongue cancer. Br J Cancer 92: 1915-1921, 2005.

28. Tanaka C, Uzawa K, Shibahara T, Yokoe H, Noma H and Tanzawa H: Expression of an inhibitor of apoptosis, survivin, in oral carcinogenesis. J Dent Res 82: 607-611, 2003.

29. Ayer DE: Histone deacetylases: transcriptional repression with SINers and NuRDs. Trends Cell Biol 9: 193-198, 1999.

30. Narlikar GJ, Fan HY and Kingston RE: Cooperation between complexes that regulate chromatin structure and transcription. Cell 108: 475-487, 2002.

31. Freiman RN and Tjian R: Regulating the regulators: lysine modifications make their mark. Cell 112: 11-17, 2003.

32. Kouzarides T: Histone methylation in transcriptional control. Curr Opin Genet Dev 12: 198-209, 2002.

33. Polevoda B and Sherman F: The diversity of acetylated proteins. Genome Biol 3: Reviews 0006: 1-6, 2002.

34. Richon VM, Sandhoff TW, Rifkind RA and Marks PA: Histone deacetylase inhibitor selectively induces p21WAF1 expression and gene-associated histone acetylation. Proc Natl Acad Sci USA 97: 10014-10019, 2000. 
35. Marks P, Rifkind RA, Richon VM, Breslow R, Miller T and Kelly WK: Histone deacetylases and cancer: causes and therapies. Nat Rev Cancer 1: 194-202, 2001.

36. Miller TA, Witter DJ and Belvedere S: Histone deacetylase inhibitors. J Med Chem 46: 5097-5116, 2003.

37. Cress WD and Seto E: Histone deacetylases, transcriptional control, and cancer. J Cell Physiol 184: 1-16, 2000.

38. Johnstone RW and Licht JD: Histone deacetylase inhibitors in cancer therapy: is transcription the primary target? Cancer Cell 4: 13-18, 2003.
39. Bali P, Pranpat M, Bradner J, et al: Inhibition of histone deacetylase 6 acetylates and disrupts the chaperone function of heat shock protein 90: a novel basis for antileukemia activity of histone deacetylase inhibitors. J Biol Chem 280: 26729-26734, 2005.

40. Voelter-Mahlknecht S and Mahlknecht U: Cloning and structural characterization of the human histone deacetylase 6 gene. Int J Mol Med 12: 87-93, 2003. 